\title{
Poorer outcome in stromal HIF-2 $\alpha$ - and CA9-positive colorectal adenocarcinomas is associated with wild-type TP53 but not with BNIP3 promoter hypermethylation or apoptosis
}

\author{
AHG Cleven', BG Wouters'², B Schutte ${ }^{3}$, AJG Spiertz', M van Engeland' and AP de Bruïne*,I \\ 'Department of Pathology, GROW - School for Oncology and Developmental Biology, University Hospital Maastricht, PO Box 5800, 6202 AZ \\ Maastricht, The Netherlands; ${ }^{2}$ Ontario Cancer Institute/PMH, Toronto, Canada and ${ }^{3}$ Department of Molecular Cell Biology, GROW - School for Oncology \\ and Developmental Biology, University Hospital Maastricht, PO Box 5800, 6202 AZ Maastricht, The Netherlands
}

\begin{abstract}
Stromal expression of hypoxia inducible factor $2 \alpha$ (HIF-2 $\alpha$ ) and carbonic anhydrase 9 (CA9) are associated with a poorer prognosis in colorectal cancer (CRC). Tumour cell death, regulated by a hypoxic stromal microenvironment, could be of importance in this respect. Therefore, we correlated apoptosis, TP53 mutational status and BNIP3 promoter hypermethylation of CRC cells with HIF- $2 \alpha$ - and CA9-related poor outcome. In a series of 195 CRCs, TP53 mutations in exons 5- 8 were analysed by direct sequencing, and promoter hypermethylation of BNIP3 was determined by methylation-specific PCR. Expressions of HIF-2 $\alpha$, CA9, p53, BNIP3 and M30 were analysed immunohistochemically. Poorer survival of HIF-2 $\alpha$ and CA9 stromal-positive CRCs was associated with wild-type TP53 $(P=0.001$ and $P=0.039$ I), but not with BNIP3 methylation. Furthermore, apoptotic levels were independent of the TP53 status, but lower in unmethylated BNIP3 CRCs $(P=0.004)$. It appears that wild-type TP53 in CRC cells favours the progression of tumours expressing markers for hypoxia in their stroma, rather than in the epithelial compartment. Preserved BNIP3 function in CRC cells lowers apoptosis, and may thus be involved in alternative cell death pathways, such as autophagic cell death. However, BNIP3 silencing in tumour cells does not impact on hypoxia-driven poorer prognosis.

These results suggest that the biology of CRC cells can be modified by alterations in the tumour microenvironment under conditions of tumour hypoxia.

British Journal of Cancer (2008) 99, 727-733. doi:I0.1038/sj.bjc.6604547 www.bjcancer.com
\end{abstract}

Published online 19 August 2008

(c) 2008 Cancer Research UK

Keywords: colorectal cancer; hypoxia; TP53; BNIP3; outcome

Hypoxia has been reported to influence tumour biology in opposing ways. It can directly induce cell death by activating apoptosis or autophagy, yet hypoxic zones in solid tumours also harbour viable cells resistant to treatment, which contributes to poor patient outcome (Erler et al, 2006). Hypoxia influences the expression of genes involved in cell death and energy homeostasis mainly by stabilisation and activation of the hypoxia inducible factor (HIF) family of transcription factors, influencing angiogenesis (VEGF), glycolysis (GLUT1), pH regulation (CA9), apoptosis (TP53, BNIP3) and autophagy (BNIP3) (Bacon and Harris, 2004; Keith and Simon, 2007).

A common hallmark of solid tumours under hypoxic stress is increased ATP requirement, which is supplied by the induction of anaerobic glycolysis. This subsequently leads to a high production of intracellular lactate, requiring regulation of intracellular $\mathrm{pH}$, a process mediated partly by HIF-dependent upregulation of carbonic anhydrase 9 (CA9). Carbonic anhydrase 9 catalyzes the extracellular trapping of acid by hydrating cell-generated $\mathrm{CO}_{2}$ into $\mathrm{HCO}_{3}^{-}$and $\mathrm{H}^{+}$(Swietach et al, 2007). Consequently,

*Correspondence: Dr AP de Bruïne; E-mail: adb@lpat.azm.nl Received 14 April 2008; revised I July 2008; accepted 10 July 2008; published online 19 August 2008
CA9 expression may serve as a marker for metabolic adaptation during hypoxia.

Upregulation of p53 and BNIP3 proteins, which stimulate cell death via apoptosis and/or autophagy, appears contradictory to the adverse association between tumour hypoxia and prognosis. However, it was suggested that through induction of cell death, hypoxia selects for cells with defective cell death regulators, such as TP53 (Graeber et al, 1996). In non-selected cells hypoxia can induce expression of $p 53$ and activate $p 53$-mediated $G_{0} / G_{1}$ arrest or apoptosis, although secondary effects, such as extracellular acidosis and glucose deprivation, are necessary for p53-mediated apoptosis (Graeber et al, 1996; Schmaltz et al, 1998; Pan et al, 2004; Toledo and Wahl, 2006). Over $50 \%$ of human tumours contain somatic mutations in the TP53 gene, resulting in a defective apoptotic response (Kato et al, 2003; Soussi and Lozano, 2005). Therefore, TP53 mutations are expected to decrease the susceptibility of tumour cells to hypoxia-induced cell death, as shown in vitro (Graeber et al, 1996; Fei et al, 2004). BNIP3 is a Bcl-2 family member, containing a single BcL-2 homology 3 (BH3) domain and a transmembrane domain localising it to the outer mitochondrial membrane (Vande Velde et al, 2000; Lee and Paik, 2006). It is activated by HIF during hypoxia and initiates programmed cell death through apoptosis or autophagy (Ray et al, 2000; Mellor and Harris, 2007). Epigenetic silencing of BNIP3 by promoter 
hypermethylation has been reported in several cancer types and contributes to resistance to hypoxia-induced cell death (Okami et al, 2004; Abe et al, 2005; Yan et al, 2006). The role of BNIP3 in colorectal cancer (CRC) is unknown, although $66 \%$ tumours show BNIP3 silencing by promoter hypermethylation (Murai et al, 2005; Bacon et al, 2007).

Usually, the effects of hypoxia in solid tumours are studied within the tumour cells themselves, neglecting the hypoxic response in tumour-associated stroma. In a previous study, we found that hypoxia within the tumour-associated stroma is indeed correlated with a poorer outcome in patients with CRC who are treated by surgery alone. In a multivariate model, stromal expressions of both HIF- $2 \alpha$ and CA9 were independent adverse prognostic factors, whereas HIF- $1 \alpha$ was not. Furthermore, expression of hypoxia-related proteins HIF- $1 \alpha$, GLUT1 and CA9 in the tumour cells self was not associated with poorer patient survival (Cleven et al, 2007).

Our previous findings indicate that hypoxic conditions may modulate the tumour stroma in such a way that a more aggressive tumour behaviour is facilitated, ultimately leading to decreased patient survival.

This study attempts to elucidate whether changes in the epithelial cell compartment of CRC, such as apoptosis and concomitant (epi)genetic changes that are confined to the tumour cells, are related to hypoxia-related changes in the stromal compartment. For this purpose, we correlated alterations of TP53 and BNIP3 in tumour cells with expression of hypoxia-related proteins HIF- $2 \alpha$ and CA9 in relation with patient outcome and apoptotic activity in CRCs.

\section{PATIENTS AND METHODS}

\section{Patient population}

Patients were registered for two multicentre prospective clinical trials in The Netherlands between 1979 and 1981. One trial was designed to compare patient survival after treatment of colon cancer by conventional surgery or the no-touch isolation technique (Wiggers et al, 1988). The second trial was conducted to compare survival in rectal cancer patients with or without preoperative radiotherapy. In the current study, we included only the patients who did not undergo preoperative radiotherapy. At the time the trial was conducted, only surgical removal of the tumours was performed, and adjuvant chemotherapy was not yet a standard practice. This study population therefore enables unbiased study of the influence of hypoxic conditions on tumour biology.

Tumour tissues were fixed in buffered formalin, sectioned and embedded in paraffin. Experienced pathologists documented the histopathological characteristics of the tumours (Table 1). Follow-up took place every 3 months during the first 3 years and every 6 months between 3 and 5 years after initial diagnosis and surgery. Standard protocols were followed, with routine blood counts and chemical studies (including CEA levels) at each visit, and liver ultrasound, chest X-ray and colonoscopy annually, to evaluate recurrence of disease and disease-related death. After a 5-year follow-up period, only time and cause of death were registered. Follow-up was complete for all patients. Failure was defined as death due to recurrent disease, excluding postoperative mortality within 30 days and non-disease-related death.

For immunohistochemical and molecular analyses, tumour tissues from 195 CRC patients were available. The distribution of age, gender, tumour stage, location and type of tumour, frequency of events and mean follow-up time of the patients in this study are representative of the patients in the trial (see Table 1).
Table I TP53 mutation analyses, BNIP3 methylation and clinicopathological characteristics

\begin{tabular}{|c|c|c|c|c|c|c|c|c|c|c|}
\hline & \multicolumn{4}{|c|}{ TP53 } & \multicolumn{5}{|c|}{ BNIP3 } & \multirow[b]{3}{*}{$P$} \\
\hline & \multicolumn{2}{|c|}{ Wt } & \multicolumn{2}{|c|}{ Mutant } & \multirow[b]{2}{*}{$P$} & \multicolumn{2}{|c|}{$\mathbf{U}$} & \multicolumn{2}{|c|}{$\mathbf{M}$} & \\
\hline & No. & $\%$ & No. & $\%$ & & No. & $\%$ & No. & $\%$ & \\
\hline Total patients & 78 & (50) & 77 & (50) & & 92 & $(47)$ & 103 & (53) & \\
\hline $\begin{array}{l}\text { Age (years) } \\
\quad<69 \\
>69\end{array}$ & $\begin{array}{l}35 \\
43\end{array}$ & $\begin{array}{l}(45) \\
(55)\end{array}$ & $\begin{array}{l}41 \\
36\end{array}$ & $\begin{array}{l}(53) \\
(47)\end{array}$ & 0.297 & $\begin{array}{l}44 \\
48\end{array}$ & $\begin{array}{l}(48) \\
(52)\end{array}$ & $\begin{array}{l}47 \\
56\end{array}$ & $\begin{array}{l}(46) \\
(54)\end{array}$ & 0.759 \\
\hline $\begin{array}{l}\text { Sex } \\
\quad \text { Male } \\
\text { Female }\end{array}$ & $\begin{array}{l}35 \\
43\end{array}$ & $\begin{array}{l}(45) \\
(55)\end{array}$ & $\begin{array}{l}35 \\
42\end{array}$ & $\begin{array}{l}(45) \\
(55)\end{array}$ & 0.942 & $\begin{array}{l}42 \\
50\end{array}$ & $\begin{array}{l}(46) \\
(54)\end{array}$ & $\begin{array}{l}49 \\
54\end{array}$ & $\begin{array}{l}(48) \\
(52)\end{array}$ & 0.788 \\
\hline $\begin{array}{l}\text { Tumour location } \\
\text { Proximal } \\
\text { Distal }\end{array}$ & $\begin{array}{l}32 \\
46\end{array}$ & $\begin{array}{l}(4 I) \\
(59)\end{array}$ & $\begin{array}{l}24 \\
53\end{array}$ & $\begin{array}{l}(31) \\
(69)\end{array}$ & 0.202 & $\begin{array}{l}25 \\
67\end{array}$ & $\begin{array}{l}(27) \\
(73)\end{array}$ & $\begin{array}{l}45 \\
58\end{array}$ & $\begin{array}{l}(44) \\
(56)\end{array}$ & 0.016 \\
\hline $\begin{array}{l}\text { Tumour } \\
\text { Colon } \\
\text { Rectum }\end{array}$ & $\begin{array}{l}49 \\
29\end{array}$ & $\begin{array}{l}(63) \\
(37)\end{array}$ & $\begin{array}{l}47 \\
30\end{array}$ & $\begin{array}{l}(61) \\
(39)\end{array}$ & 0.819 & $\begin{array}{l}61 \\
31\end{array}$ & $\begin{array}{l}(66) \\
(34)\end{array}$ & $\begin{array}{l}68 \\
35\end{array}$ & $\begin{array}{l}(66) \\
(34)\end{array}$ & 0.967 \\
\hline $\begin{array}{l}\text { Differentiation } \\
\text { Well } \\
\text { Moderate/ } \\
\text { poor }\end{array}$ & $\begin{array}{c}8 \\
70\end{array}$ & $\begin{array}{l}(10) \\
(90)\end{array}$ & $\begin{array}{c}8 \\
69\end{array}$ & $\begin{array}{l}(10) \\
(90)\end{array}$ & 0.913 & $\begin{array}{l}10 \\
82\end{array}$ & $\begin{array}{l}(11) \\
(89)\end{array}$ & $\begin{array}{l}11 \\
92\end{array}$ & $\begin{array}{l}(11) \\
(89)\end{array}$ & 0.959 \\
\hline $\begin{array}{c}\text { TNM } \\
1 \\
2 \\
3 \\
4\end{array}$ & $\begin{array}{c}1 \\
40 \\
28 \\
9\end{array}$ & $\begin{array}{l}(1) \\
(51) \\
(36) \\
(12)\end{array}$ & $\begin{array}{l}2 \\
46 \\
19 \\
10\end{array}$ & $\begin{array}{l}(2) \\
(60) \\
(25) \\
(13)\end{array}$ & 0.471 & $\begin{array}{l}3 \\
61 \\
14 \\
14\end{array}$ & $\begin{array}{l}(4) \\
(66) \\
(15) \\
(15)\end{array}$ & $\begin{array}{c}1 \\
55 \\
40 \\
7\end{array}$ & $\begin{array}{l}(1) \\
(53) \\
(39) \\
(7)\end{array}$ & 0.001 \\
\hline
\end{tabular}

$\mathrm{Wt}=$ wild type; $\mathrm{U}=$ unmethylated; $\mathrm{M}=$ methylated; $\mathrm{TNM}=$ tumour, node, metastasis. Location: proximal or distal to splenic flexure.

\section{Genomic DNA isolation}

Genomic DNA was extracted from CRC tissues using PureGene ${ }^{\mathrm{TM}}$ genomic DNA isolation kit (Gentra Systems, Minneapolis, MN, USA) based on the manufacturer's protocol.

\section{TP53 sequencing}

Mutation analyses of TP53 exons 5-8 were performed using a semi-nested PCR approach, (see Supplementary Table 1 for primer sequences). Caco2 (exon 6, codon 204 nonsense mutation) was included as a control. Direct sequencing of PCR products was performed using the BigDye ${ }^{\circledR}$ terminator v1.1 cycle sequencing kit (Applied Biosystems, Foster City, CA, USA) and analysed on the ABI 3730 DNA Analyzer (Applied Biosystems). Mutation was detected using Mutation Surveyor DNA Variant Analysis Software v3.0 (SoftGenetics LLC, State College, PA, USA). The results of the mutation analyses are listed in Table 2. Furthermore, we assessed whether TP53 missense mutants were transcriptionally active, on the basis of the IARC prediction models (http://p53.iarc.fr/ MutationValidationCriteria.asp). Missense mutations were classified as either transactivation-incompetent or transactivationcompetent missense mutations.

\section{BNIP3 promoter methylation analysis}

BNIP3 promoter methylation was determined by sodium bisulphite modification of genomic DNA using the EZ DNA methylation kit (ZYMO Research Co., Orange, CA). Methylation-specific 
Table 2 Frequency and type of TP53 alterations

\begin{tabular}{lcc}
\hline TP53 Mutation & No. & $\%$ \\
\hline Wild-type & 72 & $(46)$ \\
Tr-incom missense & 57 & $(37)$ \\
Tr-com missense & 8 & $(5)$ \\
Silent & 4 & $(3)$ \\
Nonsense & 5 & $(3)$ \\
Deletion & 4 & $(3)$ \\
Insertion & 3 & $(2)$ \\
Polymorphism & 2 & $(1)$ \\
Total & 155 & $(100)$ \\
\hline
\end{tabular}

Tr-incom $=$ transactivation incompetent; $\mathrm{Tr}$-com $=$ transactivation competent.

PCR was performed as described in detail elsewhere (Herman et al, 1996; Derks et al, 2004). DNA was first amplified with BNIP3 flanking PCR primers that amplify bisulfite-modified DNA but do not preferentially amplify methylated or unmethylated DNA. The resulting template was used as the template for BNIP3 methylation-specific PCR. For primer sequences see Supplementary Table 1. All PCRs were performed with a control for unmethylated BNIP3 alleles (normal lymphocyte DNA), a positive control for methylated BNIP3 alleles (Sssl methyltransferase (New England Biolabs, Beverly, MA, USA)-treated normal lymphocyte DNA) and a negative control without DNA. Each PCR product was loaded onto a 2\% agarose gel, stained with Gelstar ${ }^{\circledR}$ (Cambrex Bioscience Rockland Inc., Rockland, ME, USA) and visualised under UV illumination.

\section{Immunohistochemistry}

Serial formalin-fixed, paraffin-embedded tissues sections $(4 \mu \mathrm{m})$ were stained for HIF-2 $\alpha$ and CA9, as described previously (Cleven et al, 2007). Brief descriptions are as follows.

HIF-2 $\alpha$ staining Antigen retrieval was performed by microwave treatment ( $750 \mathrm{~W}$ for $20 \mathrm{~min}$ in $1 \mathrm{mM}$ TE buffer, $\mathrm{pH} 8.0$ ), followed by cooling in buffer for $30 \mathrm{~min}$. Slides were blocked in $25 \%$ normal serum for $10 \mathrm{~min}$. Sections were incubated with primary antibody HIF- $2 \alpha(1: 500)$ for 100 min (anti-HIF- $2 \alpha$ monoclonal: ab8365; AbCam, Cambridge, UK).

CA9 staining Slides were blocked in $25 \%$ normal serum for $10 \mathrm{~min}$, and then incubated for $45 \mathrm{~min}$ with primary CA9 antibody MoAb M75 (1:50, anti-human CA9; kindly supplied by Dr S Pastorekova) at room temperature.

In addition to the above-mentioned staining procedures, serial sections were stained for p53, BNIP3 and M30, as follows:

p53 staining Antigen retrieval was performed by microwave treatment $(750 \mathrm{~W}$ for $15 \mathrm{~min}$ in Antigen Retrieval (DAKO, Glostrup, Denmark)), followed by cooling in buffer for $30 \mathrm{~min}$. Slides were blocked in $25 \%$ normal serum for $10 \mathrm{~min}$. Sections were incubated for $45 \mathrm{~min}$ at room temperature with primary antibody p53 (1:500, anti-p53 monoclonal (DO-7); M7001 DAKO).

BNIP3 staining Antigen retrieval was performed by microwave treatment $(750 \mathrm{~W}$ for $15 \mathrm{~min}$ in Antigen Retrieval (DAKO)), followed by cooling in buffer for $30 \mathrm{~min}$. Slides were blocked in $25 \%$ normal serum for $10 \mathrm{~min}$. Sections were incubated for $180 \mathrm{~min}$ at room temperature with primary antibody BNIP3 $(1: 400$, antiBNIP3 monoclonal (Ana40); ab10433, Abcam, Cambridge, UK).

M30 staining Antigen retrieval was performed by microwave treatment $(750 \mathrm{~W}$ for $10 \mathrm{~min}$ in Antigen Retrieval (DAKO)), followed by cooling in buffer for $30 \mathrm{~min}$. Slides were blocked in $25 \%$ normal serum for $10 \mathrm{~min}$. Sections were incubated for $45 \mathrm{~min}$ at room temperature with primary Cytodeath antibody M30 (1:50, mouse monoclonal (CloneM30); Roche Applied Science, Mannheim, Germany).

Each staining protocol was started with pre-incubating in $0.6 \%$ hydrogen peroxide for $20 \mathrm{~min}$ to block endogenous peroxidase activity. Furthermore, as a negative control, TBS buffer was used instead of primary antibody. Visualisation was performed using Dako Envision, Peroxidase, mouse System (K4001; DAKO). Powerenvision poly-HRP (50510-60307; Immunologic, Duiven, The Netherlands) was used for M30 visualisation. The slides were counterstained with haematoxylin.

\section{Evaluation of immunohistochemistry}

Evaluation for HIF- $\alpha$ and CA9 staining was performed as described previously in detail (Cleven et al, 2007). Briefly, localisation (epithelial or stromal) was scored separately. For the category stromal staining, only the stromal myofibroblasts were taken into account, not the tumour-infiltrating inflammatory cells or the lamina propria of the normal mucosa. If nuclear staining was present in $>5 \%$ of the tumour epithelial cells or stromal cells, the sample was considered positive for HIF- $2 \alpha$.

If membranous staining occurred in $>5 \%$ of the tumour epithelial cells or stromal cells, samples were considered positive for CA9 (Yoshimura et al, 2004).

TP53 and BNIP3 staining were considered positive by the presence of nuclear staining for TP53 and cytoplasmic staining for BNIP3, in $>5 \%$ of tumour cells.

M30 expression was documented as the number of positive M30 cells per square millimetre of tumour cells (counted in 10 high-power fields $(\times 100)$ per tumour) (Figures 1C and D). Apoptosis was categorised as 'low' apoptosis when the number of M30-positive cells $\leqslant 10$ (mean) and as 'high' apoptosis when the number of M30-positive cells >10 (Marijnen et al, 2003; de Bruin et al, 2006).

\section{Data analysis}

Correlations between HIF-2 $\alpha$, CA9, BNIP3, TP53, M30 and clinicopathological parameters were determined by the Pearson $\chi^{2}$ - and Fisher's exact tests, where appropriate. To evaluate the relationship between HIF-2 $\alpha$, BNIP3, TP53 and survival, KaplanMeier survival curves were calculated. Differences between groups were determined by using the Log-rank test. The end point for analyses was overall survival starting from the day of surgery. All $P$-values are two sided and $P<0.05$ was considered statistically significant. Correction for multiple comparisons was performed using the Bonferroni procedure. Patients with unknown and unspecified scores have been omitted from analyses for that specific variable. SPSS 12.0 software was used for data analyses.

\section{RESULTS}

\section{TP53 mutations}

TP53 mutation analysis was successful in 155 out of $195(79 \%)$ CRCs. Out of the 155 CRCs, $72(46 \%)$ were classified as having no TP53 mutations, $4(3 \%)$ as having silent mutations and $2(1 \%)$ as having known common polymorphism (exon 6, codon 213, CGA $>$ CGG, R/R, refSNP rs1800372) (Table 2). A total of $37 \%$ (57 out of 155) CRCs were classified as transactivation-incompetent missense mutations and $5 \%$ (8 out of 155 ) CRCs as transactivationcompetent missense mutations. Correlations between TP53 and other variables did not change with respect to the predicted presence or absence of transcriptional activity of TP53 mutants. Therefore, in further analyses, CRCs were classified as TP53 wild type when no mutations, silent mutations or a known common polymorphism were found, and as mutant TP53 when CRCs had 
A

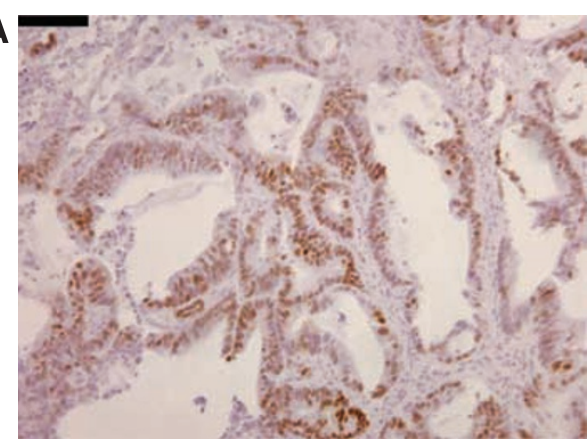

c

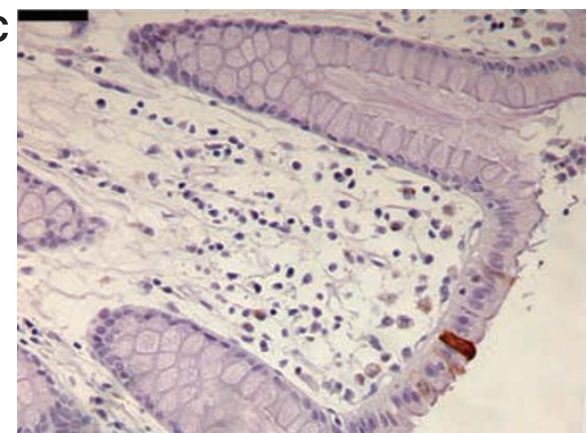

B
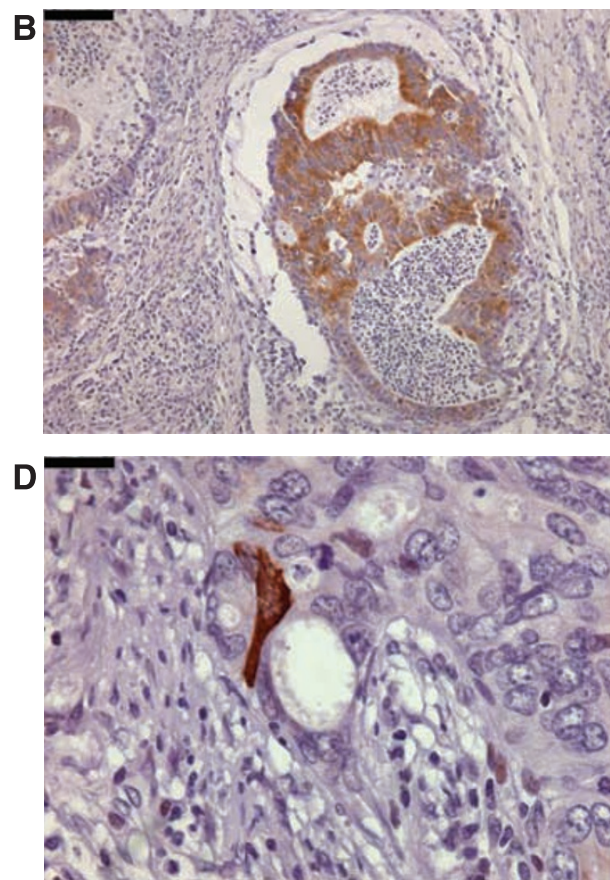

Figure I (A) Nuclear expression of p53 in colorectal tumour epithelial cells. (B) Cytoplasmic expression of BNIP3 in colorectal tumour epithelial cells. (C, D) Expression of M30 in colorectal tissue. (C) Expression of M30 in normal colon tissue. (D) Expression of M30 in tumour epithelial cell. (A, B) Original magnification $\times 20$; $(\mathbf{C}, \mathbf{D})$ original magnification $\times 40$. Black bar pictures: $(\mathbf{A}, \mathbf{B}) 200 \mu \mathrm{m}$; (C, D) $100 \mu \mathrm{m}$.

either missense, nonsense or frame-shift mutations. Using this classification, 77 out of 155 (50\%) CRCs showed TP53 mutations (Table 1), which is in agreement with data published by others (Cripps et al, 1994; Pricolo et al, 1997; Borresen-Dale et al, 1998; Kressner et al, 1999; Tortola et al, 1999; Garrity et al, 2004; Tang et al, 2004; Conlin et al, 2005; Mollevi et al, 2007; Petitjean et al, 2007).

p53 protein expression was only observed in the nucleus of epithelial cells (Figure 1A). There was a significant correlation between the absence of $\mathrm{p} 53$ protein expression and wild-type TP53 $v s$ the presence of $\mathrm{p} 53$ protein in mutant TP53 $(P=0.029$; data not shown). No correlation was observed between the TP53 mutation status and clinicopathological data (Table 1).

\section{TP53 mutations, patient survival and apoptosis}

Overall, no significant survival difference was observed between wild-type and mutant TP53 CRCs (data not shown). However, the previously reported association between HIF- $2 \alpha$ - or CA9positive CRCs and poor prognosis was found to exist exclusively in wild-type TP53 CRCs $(P=0.001$ and $P=0.0829$, respectively; Figures $2 \mathrm{~A}$ and $\mathrm{B})$. Furthermore, there was a significant difference in survival between stromal CA9 expression (38\%, 5-year survival) and epithelial CA9 expression (71\%, 5-year survival) within wild-type TP53 tumours $(P=0.0391$, data not shown). Overall levels of HIF- $2 \alpha$ or CA9 expression were not different between wild-type and mutant TP53 CRCs (data not shown). Survival of mutant TP53 CRCs was not related to HIF- $2 \alpha$ or CA9 expression $(P=0.9312$ and $P=0.8456$, respectively; Figures $2 \mathrm{E}$ and $\mathrm{F})$. These data suggest that wild-type TP53 CRCs are less susceptible to the adverse effects of hypoxia. As TP53 can induce apoptosis during hypoxia, we assessed the extent of apoptosis (M30 staining; Figures $1 \mathrm{C}$ and D). Overall, we found no differences in apoptotic levels between wild-type and mutant TP53 CRCs (Table 3), or between HIF- $2 \alpha$ - and CA9-positive or -negative CRCs (data not shown). This was found regardless of the TP53 mutation status. These results indicate that the presence or absence of functional p53 protein is not decisive for determining the extent of apoptosis in CRCs.

\section{BNIP3 methylation}

$B N I P 3$ promoter methylation analysis was successful in all of the 195 CRCs (100\%). Overall, 53\% (103 out of 195) CRCs showed BNIP3 promoter hypermethylation (Table 1), which is in agreement with data published earlier (Murai et al, 2005; Lee and Paik, 2006).

The relationship between protein expression of BNIP3 and $B N I P 3$ promoter methylation status was analysed in a randomly selected subset of patients $(n=31)$. BNIP3 protein expression was only observed in the cytoplasm of epithelial cells (Figure 1B). BNIP3 promoter-methylated CRCs less frequently demonstrated BNIP3 protein expression than unmethylated CRCs (25 vs $75 \%$, respectively).

\section{BNIP3 methylation, patient survival and apoptosis}

Overall, there was no significant survival difference between BNIP3 methylated and unmethylated CRCs (data not shown). Although in HIF- $2 \alpha$ stromal-negative CRCs, BNIP3 methylation occurred in $61 \%$ (33 out of 54 ) and did not influence prognosis, in the HIF- $2 \alpha-$ positive tumours, methylation was observed at almost equal frequency, $52 \%$ (68 out of 132), but was associated with poorer patient survival $(P=0.006$; Figure $2 \mathrm{G})$. Similarly, exclusively stromal (and not epithelial) expression of CA9 was an indicator of a poorer prognosis in both BNIP3 methylated and unmethylated tumours $(P=0.0495$ and $P=0.0725$, respectively; Figures $2 \mathrm{D}$ and $\mathrm{H})$.

This suggests that hypoxic CRCs with stromal expression of HIF- $2 \alpha$ and CA9 have a poorer prognosis, independent of BNIP3 methylation.

As BNIP3 has been reported to induce apoptosis in response to hypoxia, its methylation and associated downregulation might be expected to result in less apoptosis in the HIF- $2 \alpha$ subgroup. However, a low apoptotic activity (low M30 expression) was 
A

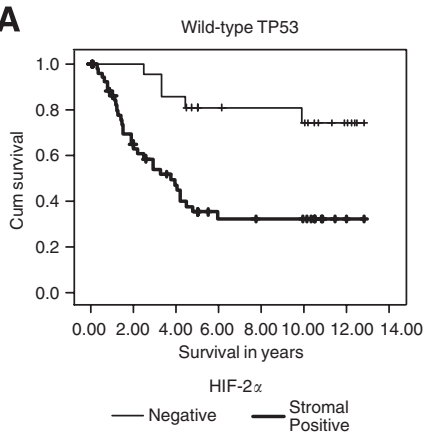

E

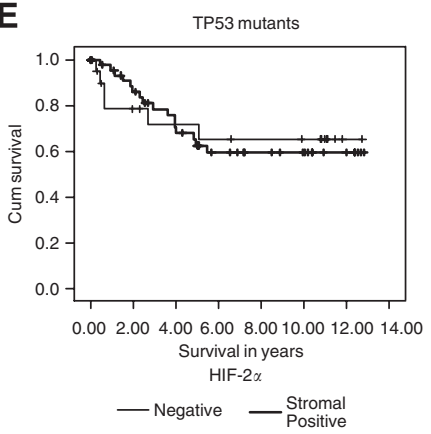

B

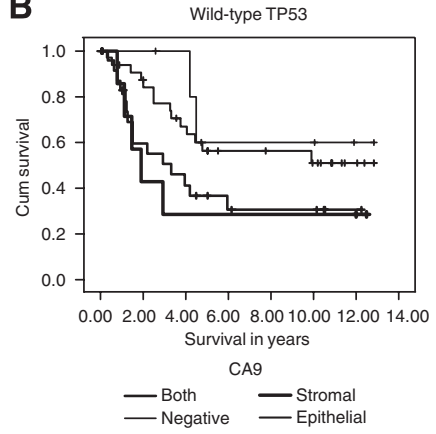

$\mathbf{F}$

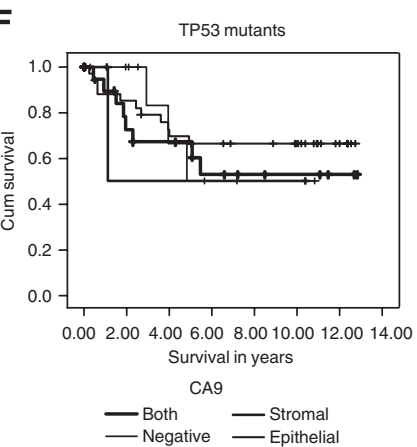

C

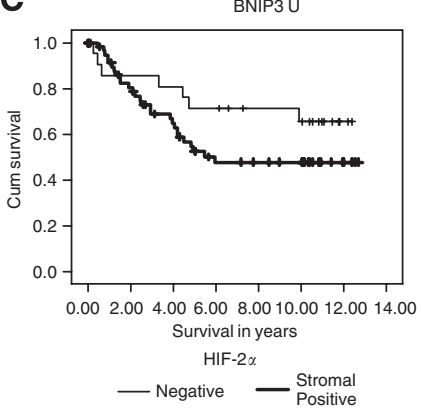

G

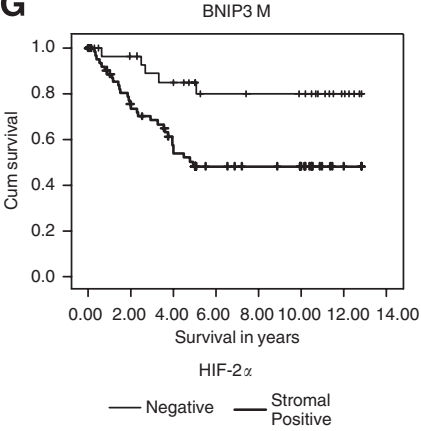

D

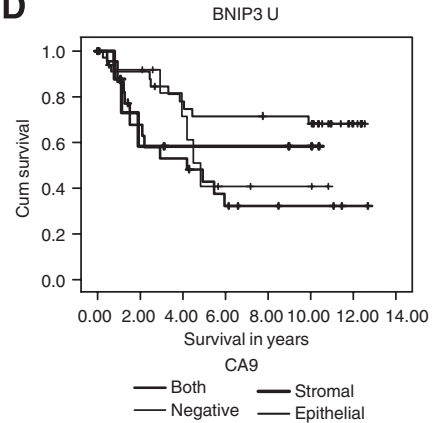

H

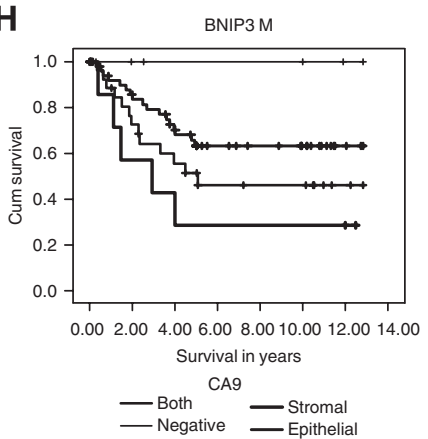

Figure 2 Survival curves. (A) HIF-2 $\alpha$ expression in wild-type TP53 group $(P=0.00 \mathrm{I}, n=75)$. (B) CA9 expression in wild-type TP53 group ( $P=0.0829$, $n=72)$. (C) HIF-2 $\alpha$ expression in BNIP3 unmethylated group $(P=0.1712, n=83)$. (D) CA9 expression in BNIP3 unmethylated group $(P=0.0725, n=79)$. (E) HIF-2 $\alpha$ expression in mutant TP53 group $(P=0.9312, n=69)$. (F) CA9 expression in mutant TP53 group $(P=0.8456, n=7$ I). $(\mathbf{G}) \mathrm{HIF}-2 \alpha$ expression in BNIP3 methylated group $(P=0.006, n=98)$. $(\mathbf{H})$ CA9 expression in BNIP3 methylated group $(P=0.0495, n=95)$. $U$, unmethylated; M, methylated.

Table 3 Correlations between BNIP3 methylation and TP53 alteration vs M30 expression

\begin{tabular}{lllllll}
\hline & \multicolumn{2}{c}{ M30 low } & & \multicolumn{2}{c}{ M30 high } & \\
\cline { 2 - 3 } & No. & $\%$ & & No. & $\%$ & P \\
\hline BNIP3 & & & & & \\
$\quad$ Unmethylated & 50 & $(68)$ & & 23 & $(32)$ & 0.004 \\
Methylated & 42 & $(46)$ & & 49 & $(54)$ & \\
TP53 & & & & & \\
$\quad$ Wild-type & 39 & $(56)$ & & 31 & $(44)$ & 0.703 \\
Mutation & 36 & $(59)$ & & 25 & $(41)$ & \\
\hline
\end{tabular}

detected more frequently in BNIP3 unmethylated CRCs 68\% (50 out of 73) compared with BNIP3 methylated CRCs $46 \%$ (42 out of 91, $P=0.004$; Table 3). Although tumours with both methylated $B N I P 3$ and stromal HIF- $2 \alpha$ expression showed a poorer patient survival when compared with HIF- $2 \alpha$-negative tumours, this was not related to apoptosis (data not shown). Furthermore, we did not detect differences in apoptotic levels between tumours with or without CA9 expression, regardless of the BNIP3 methylation status.

\section{DISCUSSION}

In a previous study on the expression of hypoxia-related markers (HIF1 $\alpha$, HIF2 $\alpha$, CA9 and GLUT1) in colorectal adenocarcinomas, we found that in all tumours at least one of these proteins is immunohistochemically expressed. This indicates that hypoxia is an all but ubiquitous phenomenon in colorectal tumours. However, expression of only HIF $2 \alpha$ and CA9 in the tumour-associated stroma was correlated with a poorer prognosis, suggesting that tumours with this particular phenotype follow a more aggressive course (Cleven et al, 2007). These results are in contrast to some other studies on colon and rectum tumours that can be summarised by the observation that HIF $1 \alpha$ and GLUT1 expression in rectal cancer cells is of prognostic significance (Haber et al, 1998; Yoshimura et al, 2004; Lu et al, 2006; Theodoropoulos et al, 2006). Our finding was relatively new, in the sense that others have mainly reported the relation between tumour prognosis and expression of hypoxia markers in cancer cells, without paying attention to stromal expression. The results in our study did not differ between tumours of the colon and rectum.

So far, the biological basis of stromal expression of hypoxiarelated markers in CRC is unclear. It could either be a serendipitous finding, or a genuine indication of altered epithelial-mesenchymal interactions within a subset of tumours. In these tumours, hypoxia-driven metabolic and cell biological changes could hypothetically alter the tumour stroma toward an environment that can facilitate cancer progression, along multiple routes, leading to an enhanced proliferation or survival of tumour epithelial cells (Beppu et al, 2008). Under hypoxic conditions, the tumour stroma can select for the propagation of certain subclones of cancer cells that are optimally endowed for tumour progression. A recent study on breast cancer, on how changes in stromal gene expression affect epithelial tumour progression, showed that gene expression profiling of microdissected tumour stroma resulted in a set of stromal genes, which could predict clinical outcome. This set notably included enhanced stromal expression of hypoxiaassociated genes (Finak et al, 2008).

The current study attempts to pinpoint specific genetic and epigenetic features of CRC cells, which are both associated with the observed more aggressive presentation of CRCs expressing HIF $2 \alpha$ and CA9 in their surrounding stroma, and impact on one of the hallmarks of cancer, namely regulation of apoptosis under hypoxic conditions. 
Tumour hypoxia results in the induction of pro-death signals, mediated partly by TP53 and BNIP3 (Brahimi-Horn and Pouyssegur, 2006). Therefore, it could be envisaged that hypoxia provides a selective environment for outgrowth of cells in which these genes have become mutated or silenced. Loss of pro-death genes, such as TP53 and BNIP3, may result in increased hypoxia tolerance and cross-resistance to other death-inducing stimuli associated with metabolic stress or treatment. Immunohistochemical staining showed that TP53 and BNIP3 expressions are confined to the epithelial cell compartment in CRC, and are not present in the surrounding mesenchymal cells, making these two genes interesting candidates to study the hypothesis of cancer cell selection under hypoxia-driven modification of tumour-stroma interactions.

Intriguingly, our results indicate that tumours expressing HIF$2 \alpha$ or CA9 in their stroma have a poorer prognosis in wild-type TP53 tumours compared with mutant tumours. It is unclear as to how wild-type TP53 might benefit this tumour subgroup, but several possibilities exist. Firstly, p53 is involved in a metabolic switch to glycolysis when oxidative phosphorylation is impaired during hypoxia (Lum et al, 2007). Also, other means of adaptation to metabolic stress, such as increased fatty acid $\beta$ oxidation, have been shown to be present in tumour cells with intact p53. With respect to this, increased apoptosis was reported in p53-deficient HCT-116 CRC cells as compared with wild-type p53 HCT-116 cells, when challenged by metabolic stress (Buzzai et al, 2007). The second possibility is that wild-type TP53 does not act directly, but simply correlates with defects in another pathway, such as the BNIP3 cell death pathway, which substitutes for TP53 loss in a similar fashion during carcinogenesis.

With respect to apoptosis- and hypoxia-driven tumour progression, we did not find important effects related to the mutational status of TP53. However, apoptotic levels were lower in BNIP3expressing tumours, when compared with tumours with epigenetically silenced BNIP3 $(P=0.004)$, which is somewhat surprising given the fact that functional BNIP3 is thought to induce cell death downstream of hypoxia inducible transcription factors. Apparently, things are more complicated. BNIP3 may not be restricted to regulation of apoptosis, but could also regulate other pathways, such as autophagy, in which there is a delicate balance between cell survival and cell death (Papandreou et al, 2005). Conceivably, the lower apoptotic activity in tumours with functional BNIP3 might be due to autophagic rescue of the tumour cells. Furthermore, BNIP3 levels appear to modulate cell death not only via apoptosis or autophagy, but also via necrosis. Also, the net effect of BNIP3 is determined by the level of expression: too high BNIP3 expression

\section{REFERENCES}

Abe T, Toyota M, Suzuki H, Murai M, Akino K, Ueno M, Nojima M, Yawata A, Miyakawa H, Suga T, , Ito H, , Endo T, Tokino T, Hinoda Y, Imai K (2005) Upregulation of BNIP3 by 5 -aza- 2 -deoxycytidine sensitizes pancreatic cancer cells to hypoxia-mediated cell death. J Gastroenterol 40: $504-510$

Bacon AL, Fox S, Turley H, Harris AL (2007) Selective silencing of the hypoxia-inducible factor 1 target gene BNIP3 by histone deacetylation and methylation in colorectal cancer. Oncogene 26: 132-141

Bacon AL, Harris AL (2004) Hypoxia-inducible factors and hypoxic cell death in tumour physiology. Ann Med 36: $530-539$

Beppu H, Mwizerwa ON, Beppu Y, Dattwyler MP, Lauwers GY, Bloch KD, Goldstein AM (2008) Stromal inactivation of BMPRII leads to colorectal epithelial overgrowth and polyp formation. Oncogene 27: 1063-1070

Borresen-Dale AL, Lothe RA, Meling GI, Hainaut P, Rognum TO, Skovlund E (1998) TP53 and long-term prognosis in colorectal cancer: mutations in the L3 zinc-binding domain predict poor survival. Clin Cancer Res 4: $203-210$

Brahimi-Horn C, Pouyssegur J (2006) The role of the hypoxia-inducible factor in tumor metabolism growth and invasion. Bull Cancer 93: $\mathrm{E} 73-\mathrm{E} 80$ will lead to autophagic cell death, whereas lower levels of BNIP3 expression, as in cells where BNIP3 is silenced, will induce necrosis (Tracy et al, 2007). In our study, we used the immunohistochemical marker M30, which exclusively measures apoptotic cell death, and thus were not able to differentiate between other forms of cell death, such as autophagic death and necrosis (Leers et al, 1999; Ueno et al, 2005).

Summarising the results from the current study, levels of apoptosis do not play an important role in determining the poorer prognosis of hypoxic CRCs, as defined by stromal expression of HIF- $2 \alpha$ and CA9. However, the latter phenotype is correlated with the presence of wild-type TP53 in the tumour cells, and the presence of functional p53 does indeed appear to have an important impact on poorer prognosis. This prognostic effect is not established through regulation of programmed tumour cell death, but may rather be connected to an enhanced capacity for adequate adaptation to metabolic stress. As TP53 mutations occur in a relatively early stage of colorectal carcinogenesis, the potential deleterious effects of hypoxia on CRC biology may already be programmed in a very early phase of tumour development.

As opposed to TP53, functionally or epigenetically silenced $B N I P 3$ did not turn out to be of influence in determining tumour prognosis. Furthermore, preservation of BNIP3 function was shown to decrease apoptotic activity, and may thus be involved in enhanced cell survival through autophagic rescue, or could be implicated in alternative cell death pathways, such as autophagic cell death or necrosis, which we were unable to measure in our experimental approach.

The findings in this translational study, on the relation between expression patterns of hypoxia-related markers in clinical samples of CRC and the functional status of genetically or epigenetically modified proteins involved in regulation of tumour cell death on the one hand and patient outcome on the other, open up interesting new avenues for more fundamental studies on the mechanisms underlying tumour hypoxia-induced changes in epithelial-mesenchymal interactions.

Understanding the mechanisms by which hypoxic tumours can overcome cell death signals and adapt through metabolic changes is critical for our understanding of tumour progression and development of effective therapeutics in CRC patients with adverse prognostic profiles.

Supplementary Information accompanies the paper on British Journal of Cancer website (http://www.nature.com/bjc)
Buzzai M, Jones RG, Amaravadi RK, Lum JJ, DeBerardinis RJ, Zhao F, Viollet B, Thompson CB (2007) Systemic treatment with the antidiabetic drug metformin selectively impairs p53-deficient tumor cell growth. Cancer Res 67: 6745-6752

Cleven AH, van Engeland M, Wouters BG, de Bruine AP (2007) Stromal expression of hypoxia regulated proteins is an adverse prognostic factor in colorectal carcinomas. Cell Oncol 29: 229-240

Conlin A, Smith G, Carey FA, Wolf CR, Steele RJ (2005) The prognostic significance of K-ras, p53, and APC mutations in colorectal carcinoma. Gut 54: $1283-1286$

Cripps KJ, Purdie CA, Carder PJ, White S, Komine K, Bird CC, Wyllie AH (1994) A study of stabilisation of p53 protein versus point mutation in colorectal carcinoma. Oncogene 9: 2739-2743

de Bruin EC, van de Velde CJ, van de Pas S, Nagtegaal ID, van Krieken JH, Gosens MJ, Peltenburg LT, Medema JP, Marijnen CA (2006) Prognostic value of apoptosis in rectal cancer patients of the Dutch total mesorectal excision trial: radiotherapy is redundant in intrinsically high-apoptotic tumors. Clin Cancer Res 12: 6432-6436

Derks S, Lentjes MH, Hellebrekers DM, de Bruine AP, Herman JG, van Engeland M (2004) Methylation-specific PCR unraveled. Cell Oncol 26: 291-299 
Erler JT, Bennewith KL, Nicolau M, Dornhofer N, Kong C, Le QT, Chi JT, Jeffrey SS, Giaccia AJ (2006) Lysyl oxidase is essential for hypoxiainduced metastasis. Nature 440: $1222-1226$

Fei P, Wang W, Kim SH, Wang S, Burns TF, Sax JK, Buzzai M, Dicker DT, McKenna WG, Bernhard EJ, El-Deiry WS (2004) Bnip3L is induced by p53 under hypoxia, and its knockdown promotes tumor growth. Cancer Cell 6: $597-609$

Finak G, Bertos N, Pepin F, Sadekova S, Souleimanova M, Zhao H, Chen H, Omeroglu G, Meterissian S, Omeroglu A, Hallett M, Park M (2008) Stromal gene expression predicts clinical outcome in breast cancer. Nat Med 14: 518-527

Garrity MM, Burgart LJ, Mahoney MR, Windschitl HE, Salim M, Wiesenfeld M, Krook JE, Michalak JC, Goldberg RM, O'Connell MJ, Furth AF, Sargent DJ, Murphy LM, Hill E, Riehle DL, Meyers CH, Witzig TE (2004) Prognostic value of proliferation, apoptosis, defective DNA mismatch repair, and p53 overexpression in patients with resected Dukes' B2 or C colon cancer: a North Central Cancer Treatment Group Study. J Clin Oncol 22: $1572-1582$

Graeber TG, Osmanian C, Jacks T, Housman DE, Koch CJ, Lowe SW, Giaccia AJ (1996) Hypoxia-mediated selection of cells with diminished apoptotic potential in solid tumours. Nature 379: 88-91

Haber RS, Rathan A, Weiser KR, Pritsker A, Itzkowitz SH, Bodian C, Slater G, Weiss A, Burstein DE (1998) GLUT1 glucose transporter expression in colorectal carcinoma: a marker for poor prognosis. Cancer 83: 34-40

Herman JG, Graff JR, Myohanen S, Nelkin BD, Baylin SB (1996) Methylation-specific PCR: a novel PCR assay for methylation status of CpG islands. Proc Natl Acad Sci USA 93: 9821-9826

Kato S, Han SY, Liu W, Otsuka K, Shibata H, Kanamaru R, Ishioka C (2003) Understanding the function-structure and function-mutation relationships of p53 tumor suppressor protein by high-resolution missense mutation analysis. Proc Natl Acad Sci USA 100: 8424-8429

Keith B, Simon MC (2007) Hypoxia-inducible factors, stem cells, and cancer. Cell 129: $465-472$

Kressner U, Inganas M, Byding S, Blikstad I, Pahlman L, Glimelius B, Lindmark G (1999) Prognostic value of p53 genetic changes in colorectal cancer. J Clin Oncol 17: 593-599

Lee H, Paik SG (2006) Regulation of BNIP3 in normal and cancer cells. Mol Cells 21: 1-6

Leers MP, Kolgen W, Bjorklund V, Bergman T, Tribbick G, Persson B, Bjorklund P, Ramaekers FC, Bjorklund B, Nap M, Jornvall H, Schutte B (1999) Immunocytochemical detection and mapping of a cytokeratin 18 neo-epitope exposed during early apoptosis. J Pathol 187: 567-572

Lu XG, Xing CG, Feng YZ, Chen J, Deng C (2006) Clinical significance of immunohistochemical expression of hypoxia-inducible factor- $1 \alpha$ as a prognostic marker in rectal adenocarcinoma. Clin Colorectal Cancer 5: $350-353$

Lum JJ, Bui T, Gruber M, Gordan JD, DeBerardinis RJ, Covello KL, Simon MC, Thompson CB (2007) The transcription factor HIF- $1 \alpha$ plays a critical role in the growth factor-dependent regulation of both aerobic and anaerobic glycolysis. Genes Dev 21: 1037-1049

Marijnen CA, Nagtegaal ID, Mulder-Stapel AA, Schrier PI, van de Velde CJ, van Krieken JH, Peltenburg LT (2003) High intrinsic apoptosis, but not radiation-induced apoptosis, predicts better survival in rectal carcinoma patients. Int J Radiat Oncol Biol Phys 57: 434-443

Mellor HR, Harris AL (2007) The role of the hypoxia-inducible BH3-only proteins BNIP3 and BNIP3L in cancer. Cancer Metastasis Rev 26: 553-566

Mollevi DG, Serrano T, Ginesta MM, Valls J, Torras J, Navarro M, Ramos E, Germa JR, Jaurrieta E, Moreno V, Figueras J, Capella G, Villanueva A (2007) Mutations in TP53 are a prognostic factor in colorectal hepatic metastases undergoing surgical resection. Carcinogenesis 28: 1241-1246

Murai M, Toyota M, Suzuki H, Satoh A, Sasaki Y, Akino K, Ueno M, Takahashi F, Kusano M, Mita H, Yanagihara K, Endo T, Hinoda Y, Tokino $\mathrm{T}$, Imai K (2005) Aberrant methylation and silencing of the BNIP3 gene in colorectal and gastric cancer. Clin Cancer Res 11: 1021 - 1027
Okami J, Simeone DM, Logsdon CD (2004) Silencing of the hypoxiainducible cell death protein BNIP3 in pancreatic cancer. Cancer Res 64: $5338-5346$

Pan Y, Oprysko PR, Asham AM, Koch CJ, Simon MC (2004) p53 cannot be induced by hypoxia alone but responds to the hypoxic microenvironment. Oncogene 23: 4975-4983

Papandreou I, Krishna C, Kaper F, Cai D, Giaccia AJ, Denko NC (2005) Anoxia is necessary for tumor cell toxicity caused by a low-oxygen environment. Cancer Res 65: 3171-3178

Petitjean A, Achatz MI, Borresen-Dale AL, Hainaut P, Olivier M (2007) TP53 mutations in human cancers: functional selection and impact on cancer prognosis and outcomes. Oncogene 26: 2157-2165

Pricolo VE, Finkelstein SD, Hansen K, Cole BF, Bland KI (1997) Mutated p53 gene is an independent adverse predictor of survival in colon carcinoma. Arch Surg 132: 371-374; discussion 374-5

Ray R, Chen G, Vande Velde C, Cizeau J, Park JH, Reed JC, Gietz RD, Greenberg AH (2000) BNIP3 heterodimerizes with Bcl-2/Bcl-X(L) and induces cell death independent of a Bcl-2 homology 3 (BH3) domain at both mitochondrial and nonmitochondrial sites. J Biol Chem 275: $1439-1448$

Schmaltz C, Hardenbergh PH, Wells A, Fisher DE (1998) Regulation of proliferation-survival decisions during tumor cell hypoxia. Mol Cell Biol 18: $2845-2854$

Soussi T, Lozano G (2005) p53 mutation heterogeneity in cancer. Biochem Biophys Res Commun 331: 834-842

Swietach P, Vaughan-Jones RD, Harris AL (2007) Regulation of tumor pH and the role of carbonic anhydrase 9. Cancer Metastasis Rev 26: 299-310

Tang R, Wang JY, Fan CW, Tsao KC, Chen HH, Wu CM, Chen JS, Changchien CR, Hsieh LL (2004) p53 is an independent pre-treatment markers for long-term survival in stage II and III colorectal cancers: an analysis of interaction between genetic markers and fluorouracil-based adjuvant therapy. Cancer Lett 210: $101-109$

Theodoropoulos GE, Lazaris AC, Theodoropoulos VE, Papatheodosiou K, Gazouli M, Bramis J, Patsouris E, Panoussopoulos D (2006) Hypoxia, angiogenesis and apoptosis markers in locally advanced rectal cancer. Int J Colorectal Dis 21: 248-257

Toledo F, Wahl GM (2006) Regulating the p53 pathway: in vitro hypotheses, in vivo veritas. Nat Rev Cancer 6: 909-923

Tortola S, Marcuello E, Gonzalez I, Reyes G, Arribas R, Aiza G, Sancho FJ, Peinado MA, Capella G (1999) p53 and K-ras gene mutations correlate with tumor aggressiveness but are not of routine prognostic value in colorectal cancer. J Clin Oncol 17: 1375-1381

Tracy K, Dibling BC, Spike BT, Knabb JR, Schumacker P, Macleod KF (2007) BNIP 3 is an RB/E2F target gene required for hypoxia-induced autophagy. Mol Cell Biol 27(17): 6229-6242

Ueno T, Toi M, Linder S (2005) Detection of epithelial cell death in the body by cytokeratin 18 measurement. Biomed Pharmacother 59(Suppl 2): S359-S362

Vande Velde C, Cizeau J, Dubik D, Alimonti J, Brown T, Israels S, Hakem R, Greenberg AH (2000) BNIP3 and genetic control of necrosis-like cell death through the mitochondrial permeability transition pore. Mol Cell Biol 20: $5454-5468$

Wiggers T, Jeekel J, Arends JW, Brinkhorst AP, Kluck HM, Luyk CI, Munting JD, Povel JA, Rutten AP, Volovics A et al (1988) No-touch isolation technique in colon cancer: a controlled prospective trial. $\mathrm{Br} \mathrm{J}$ Surg 75: 409-415

Yan J, Yun H, Yang Y, Jing B, Feng C, Song-bin F (2006) Upregulation of BNIP3 promotes apoptosis of lung cancer cells that were induced by $\mathrm{p} 53$. Biochem Biophys Res Commun 346: 501-507

Yoshimura H, Dhar DK, Kohno H, Kubota H, Fujii T, Ueda S, Kinugasa S, Tachibana M, Nagasue N (2004) Prognostic impact of hypoxia-inducible factors $1 \alpha$ and $2 \alpha$ in colorectal cancer patients: correlation with tumor angiogenesis and cyclooxygenase-2 expression. Clin Cancer Res 10: $8554-8560$ 